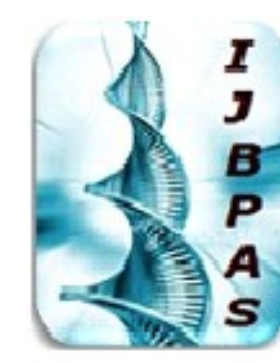

International Journal of Biology, Pharmacy and Allied Sciences (IJBPAS)

'A Bridge Betuen caboratory and QRender'

WwW.iibpas.com

\title{
ASSESSMENT OF PERIODONTAL STATUS OF FIRST MOLAR TEETH IN POST-MENOPAUSAL WOMEN
}

\section{SUNDARA MURTHY SPK ${ }^{1}$, M. JEEVITHA ${ }^{2}$ AND VENUGOPALAN $S^{3}$}

1: Saveetha Dental College and Hospitals, Saveetha Institute of Medical and Technical Sciences, Saveetha University, Chennai - 600077, India

2: Senior Lecturer, Department of Periodontics, Saveetha Dental College and Hospitals, Saveetha Institute of Medical and Technical Sciences, Saveetha University, Chennai - 600077, India

3: Reader, Department of Prosthodontics, Saveetha Dental College and Hospitals, Saveetha Institute of Medical and Technical sciences (SIMATS), Saveetha University, Chennai - 600077, India

*Corresponding Author: E Mail: Dr. M Jeevitha:jeevitham.sdc@saveetha.com

Received 20 ${ }^{\text {th }}$ March 2021; Revised 26 ${ }^{\text {th }}$ April. 2021; Accepted $24^{\text {th }}$ May 2021; Available online $1^{\text {st }}$ Aug. 2021

\section{https://doi.org/10.31032/IJBPAS/2021/10.8.1096}

\section{ABSTRACT}

Menopause is a developmental stage in women and a woman's attitude toward this transition embodies biological, psychological, and social influences. In menopause, there is a rapid decline in hormone estrogen, this leads to a lower absorption of calcium. This change causes osteoporosis, weaker bone and pocket formation in the periodontium. The aim of the present study is to assess the periodontal status of first molar teeth in postmenopausal women. This study presents the possible effects of menopause on the gingiva and periodontium involving the first molar teeth. It is a crosssectional retrospective study done by reviewing 86000 patient records, out of which case records of 100 female patients in their postmenopausal stage were considered in the study. The periodontal status of both maxillary and mandibular first molar teeth were analysed. Tooth loss in case was also recorded. All data collected were verified and analysed statistically. Periodontitis was more commonly present in maxillary first molar teeth than mandibular first molar teeth with a $p$ value of $0.025(\mathrm{p}<0.05)$. Within the limitation of this study, majority of the patients had gingivitis in mandibular first molar teeth than maxillary first molar teeth and periodontitis more commonly involved the maxillary first molar teeth.

Keywords: Gingivitis; menopause; molars; periodontitis; post-menopausal 


\section{INTRODUCTION}

Puberty, menstruation, pregnancy, and menopause are stages that occur in the life of women. These stages affect their physical condition, particularly the condition of oral cavity. Steroid sex hormones play an important role in development of periodontal disease. Oestrogen is a steroid sex hormone associated with periodontal health. Oestrogen receptors are expressed in periodontium and mucosa of oral cavity [1].

Previous studies showed a complex interaction among steroid hormones, periodontal tissues, and microorganisms in premenopausal and postmenopausal women. Perimenopause, referred to as climacteric is a period of crucial physical, emotional, psychological changes in a woman's life $[\mathbf{2}, \mathbf{3}]$. Postmenopausal oestrogen deficiency affects the immune system because it plays a role in improving body's immune system.

Postmenopause women have a higher plague index than premenopausal and perimenopausal women. This menopausal symptom is a consequence of aging and sometimes painless $[\mathbf{4}, \mathbf{5}]$. The severity of gingivitis increases at peak age of 21-30 years, whereas periodontitis increases at ages 40 years. The severity of periodontitis increases with age. Various studies have shown that the prevalence of periodontitis is generally lower in women than in men, but not in the older population.

Previously our team had conducted numerous clinical trials [6-13] and lab animal studies [13-17] and in-vitro students [18-20] over the past 5 years. Now we are focussing on epidemiological surveys.

The aim of the present study is to assess the periodontal status of first molar teeth in postmenopausal women

\section{MATERIALS AND METHODS}

\section{Study Setting}

This retrospective study was conducted under a hospital based university setting.

\section{Ethical approval}

Ethical permission and approval for the project was obtained from the Institutional Review Board of Saveetha Institute of Medical and Technical Sciences, Chennai, India on 25/04/2020. Ethical approval number is:

SDC/SIHEC/2020/DIASDATA/0619-0320.

\section{Inclusion Criteria}

All the data of the patients in this study recorded were females above the age of 51 years with periodontitis, gingivitis and missing teeth.

\section{Exclusion Criteria}

Exclusion criteria was case sheets with incomplete data, male patients, female patients below the age 51 years and those patients who did not come for follow up visits when called. 


\section{Data collection}

Data was collected from case sheets of patients who reported during the months of October 2019 and March 2020 from the hospital record management system where all the records of patients regarding their medical and dental history and treatment done are stored. All the data will be covered by the following. Cross verification was done to avoid bias by another examiner. To avoid missing any data, photographic evaluation was done. All the relevant data were retrieved and tabulated in excel sheet.

\section{Statistical Analysis}

It was statistically analysed by IBM SPSS statistics. The descriptive statistics were used to determine the frequencies and percentages of the female patients with periodontitis, gingivitis and missing teeth. Chi square test was used to assess the association of periodontal status and tooth loss involving maxillary and mandibular first molar teeth in postmenopausal patients. The outcome data was represented in the form of a bar graph.

\section{RESULTS}

The study consists of 100 patients. Female patients aged above 51 years of age checked for periodontal status. Periodontitis was more commonly seen in the right maxillary first molar $(74.75 \%)$ (Fig.1) followed by left maxillary first molar (65.66\%) (Fig.2), then left mandibular first molar (52.53\%) (Fig.3) and right mandibular first molar (49.49\%) (Fig.4). When comparing maxillary and mandibular first molar teeth, periodontitis was present more commonly in maxillary first molar teeth than mandibular first molar teeth. Gingivitis was more commonly seen in mandibular first molar teeth (right $(19.2 \%)$ and left $(14.1 \%))$ than maxillary first molar teeth (left $(12.1 \%)$ and right $(5.1 \%))$

Missing teeth was more in relation to mandibular molar teeth (left $(33.3 \%)$ and right $(31.3 \%))$ than maxillary molar teeth (left $(22.2 \%)$ and right $(20.2 \%)$ ). Periodontitis was observed more in maxillary first molar teeth than mandibular first molar teeth in all the three age groups. Gingivitis was present more in mandibular first molar teeth in age groups of 51-55 years and $>60$ years, and in the age group of 55-60 years (Fig 5-8). Gingivitis was more commonly seen in left maxillary first molar and right mandibular first molar teeth. Missing teeth were more in mandibular molar teeth than maxillary molar teeth in all the three age groups. 


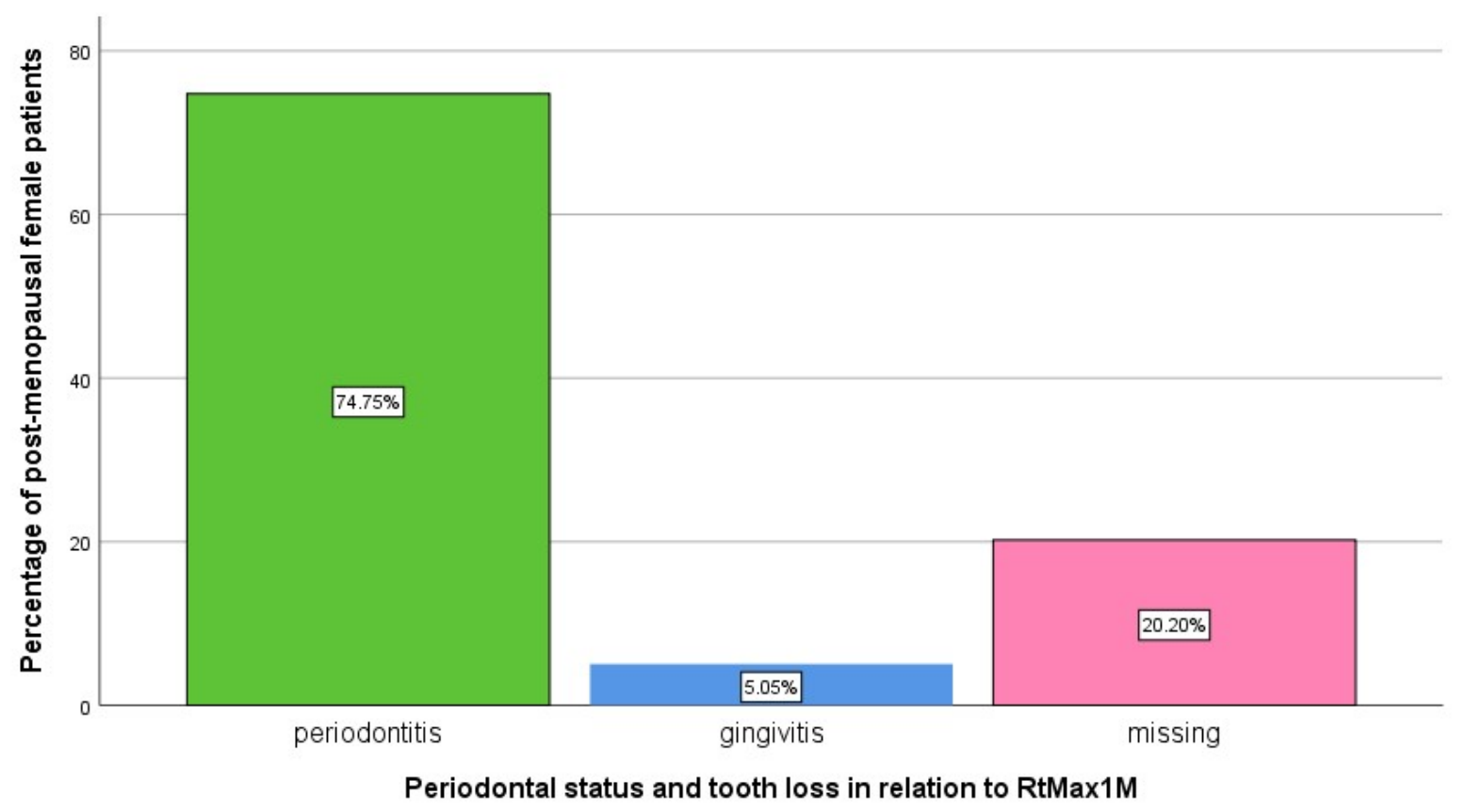

Fig.1: Bar graph represents the distribution of periodontal status and tooth loss in relation to right maxillary first molar in postmenopausal female patients. $\mathrm{X}$-axis represents the periodontal status and tooth loss in relation to the right maxillary first molar. Y-axis represents the percentage of post-menopausal female patients. From the graph it is evident that $5.05 \%$ of postmenopausal female patients present with gingivitis, $74.75 \%$ periodontitis and $20.20 \%$ of the patients present with missing teeth in relation to right maxillary first molar. (RtMax1M- right maxillary first molar).

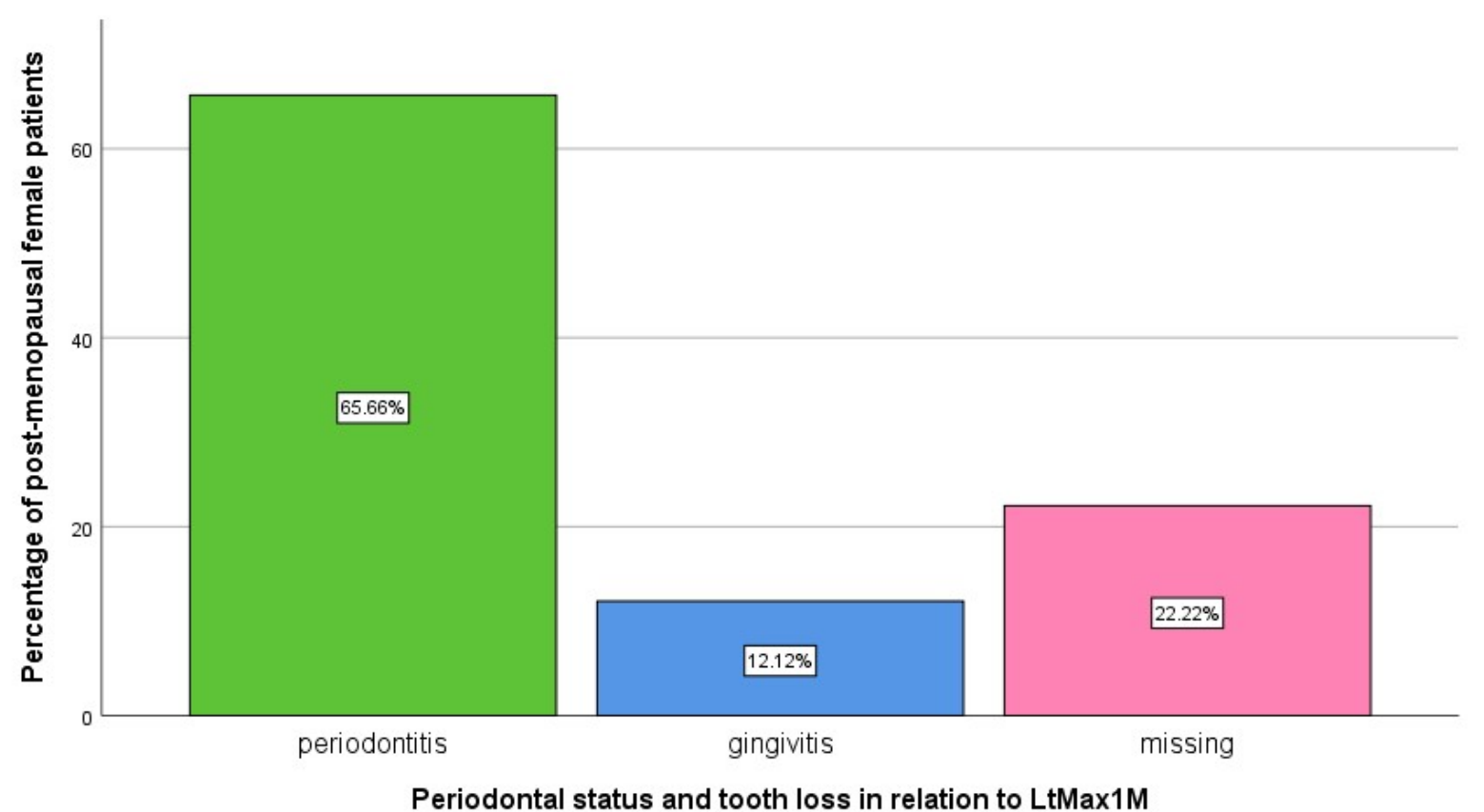

Fig.2: Bar graph represents the distribution of periodontal status and tooth loss in relation to left maxillary first molar in postmenopausal female patients. $\mathrm{X}$-axis represents the periodontal status and tooth loss in relation to the left maxillary first molar. Y-axis represents the percentage of post-menopausal female patients. From the graph it is evident that $12.12 \%$ of postmenopausal female patients present with gingivitis, $65.66 \%$ periodontitis and $22.22 \%$ of the patients present with missing teeth in relation to left maxillary first molar. (LtMax1M - Left maxillary first molar) 


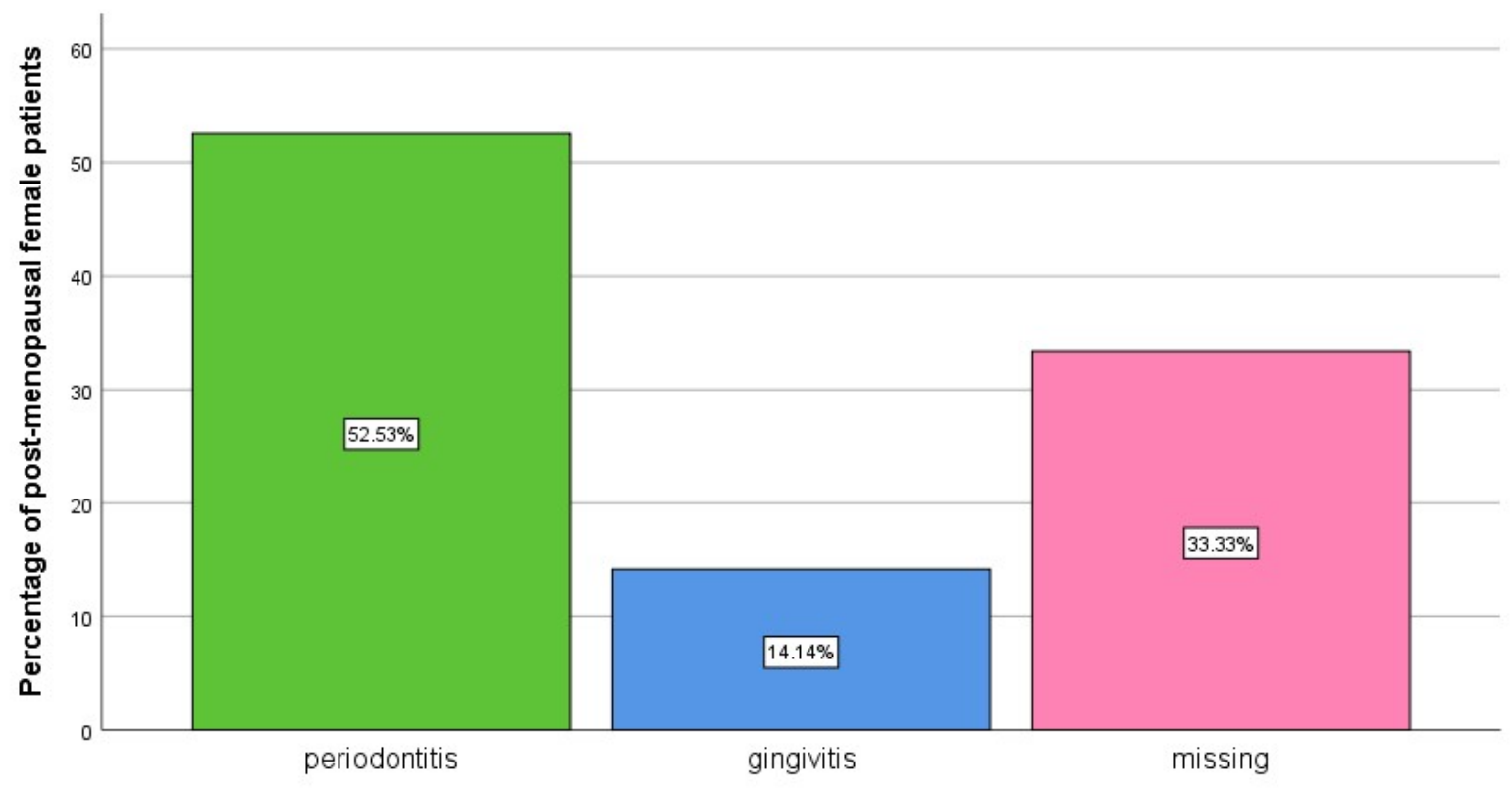

Periodontal status and tooth loss in relation to LtMan1M

Fig.3: Bar graph represents the distribution of periodontal status and tooth loss in relation to left mandibular first molar in postmenopausal female patients. $\mathrm{X}$-axis represents the periodontal status and tooth loss in relation to the left mandibular first molar. Y-axis represents the percentage of post-menopausal female patients. From the graph it is evident that $14.14 \%$ of postmenopausal female patients present with gingivitis, $52.53 \%$ periodontitis and $33.33 \%$ of the patients present with missing teeth in relation to left mandibular first molar. (LtMan1M- left mandibular first molar)

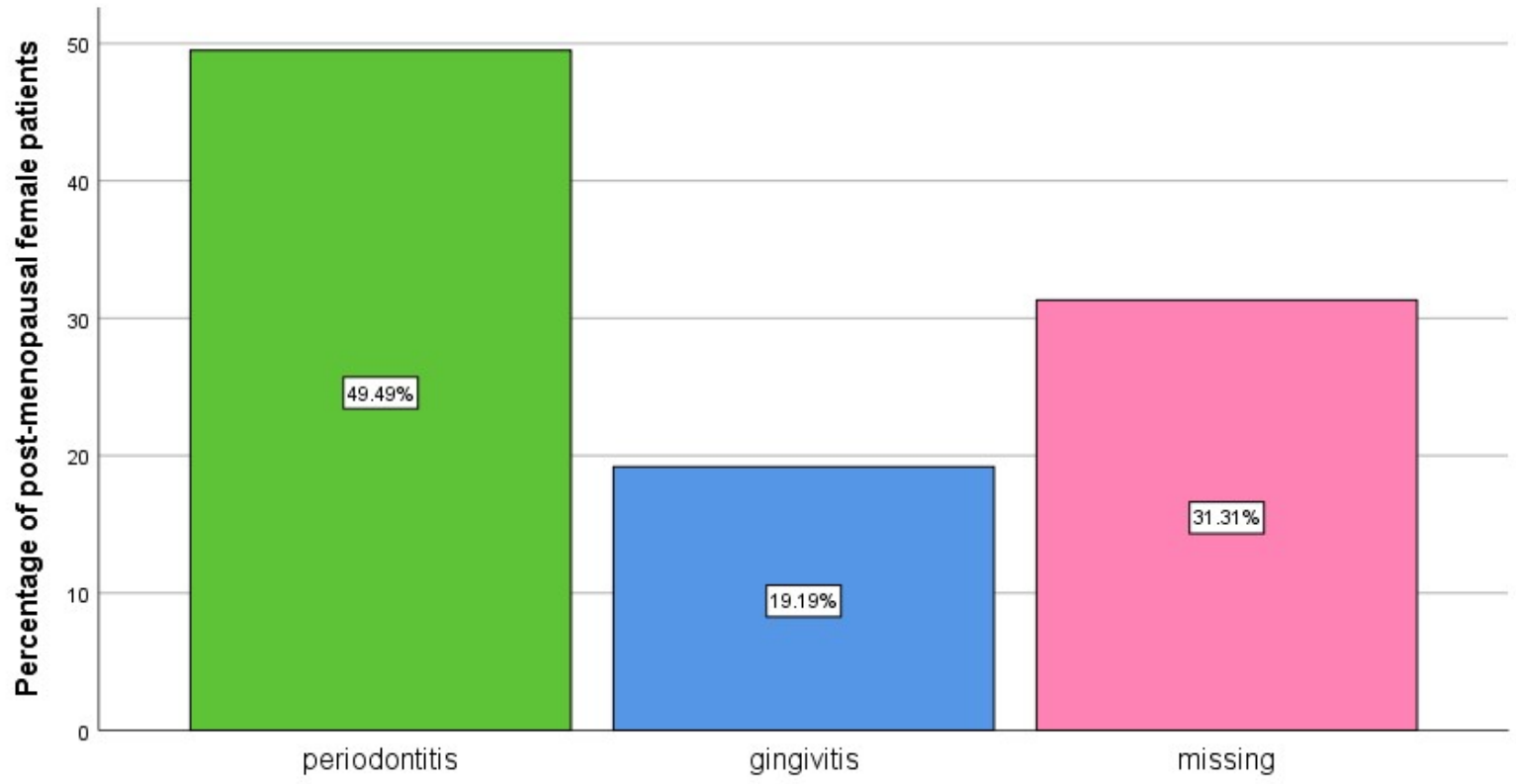

Periodontal status and tooth loss in relation to RtMan1M

Fig.4: Bar graph represents the distribution of periodontal status and tooth loss in relation to right mandibular first molar in postmenopausal female patients. $\mathrm{X}$-axis represents the periodontal status and tooth loss in relation to the right mandibular first molar. Y-axis represents the percentage of post-menopausal female patients. From the graph it is evident that $19.19 \%$ of postmenopausal female patients present with gingivitis, $49.49 \%$ periodontitis and $31.31 \%$ of the patients present with missing teeth in relation to right mandibular first molar. (RtMan1M - Right mandibular first molar) 


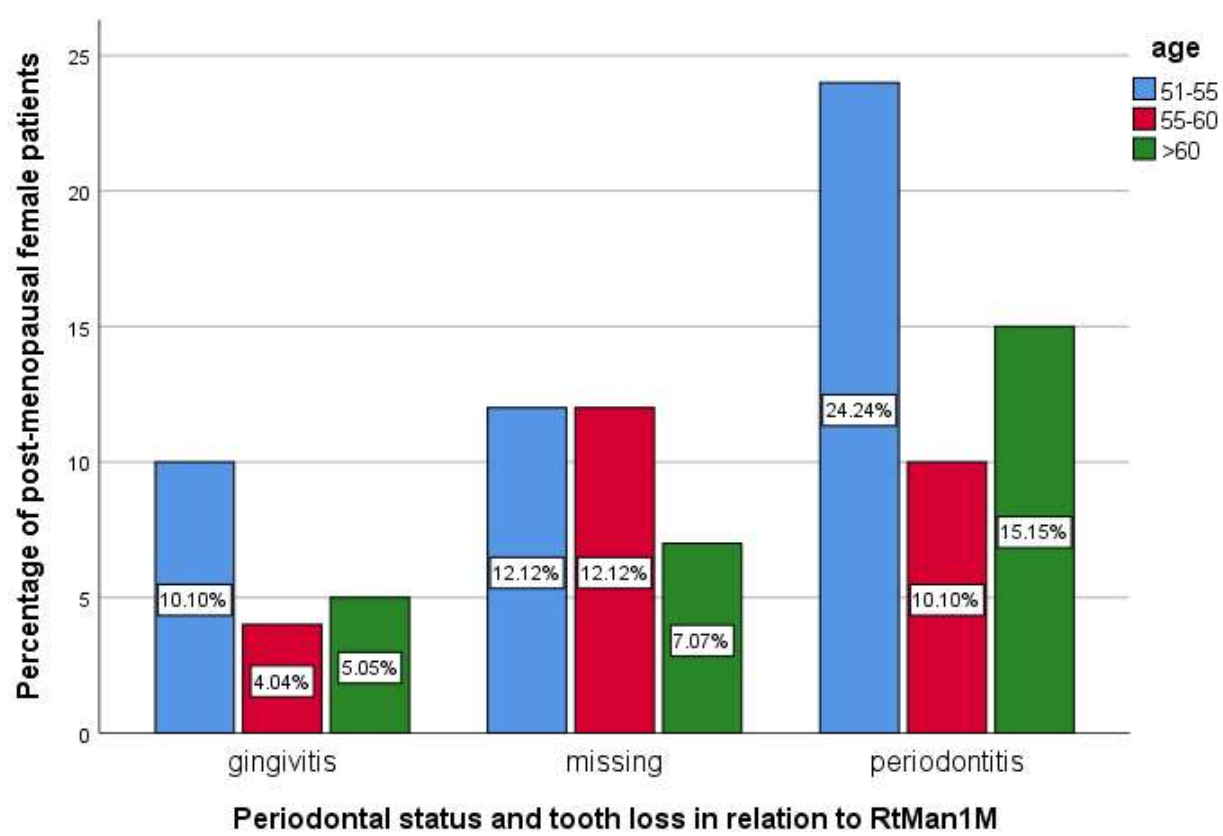

Fig. 5: Bar graphs represent the association of periodontal status and tooth loss in relation to Right mandibular first molar with age. $\mathrm{X}$-axis represents the periodontal status and tooth loss in relation to the right mandibular first molar. $\mathrm{Y}$-axis represents the percentage of post-menopausal female patients. Periodontitis in relation to right mandibular first molar was more commonly present in patients in the age group of 51-55 years than any other age group in postmenopausal stage and this difference is statistically significant. (Chi-square test, Pearson's Chi-square value: 0.442 , DF:2, p value: $0.025(p<0.05)$ which is statistically significant)). (RtMan1M - Right mandibular first molar)

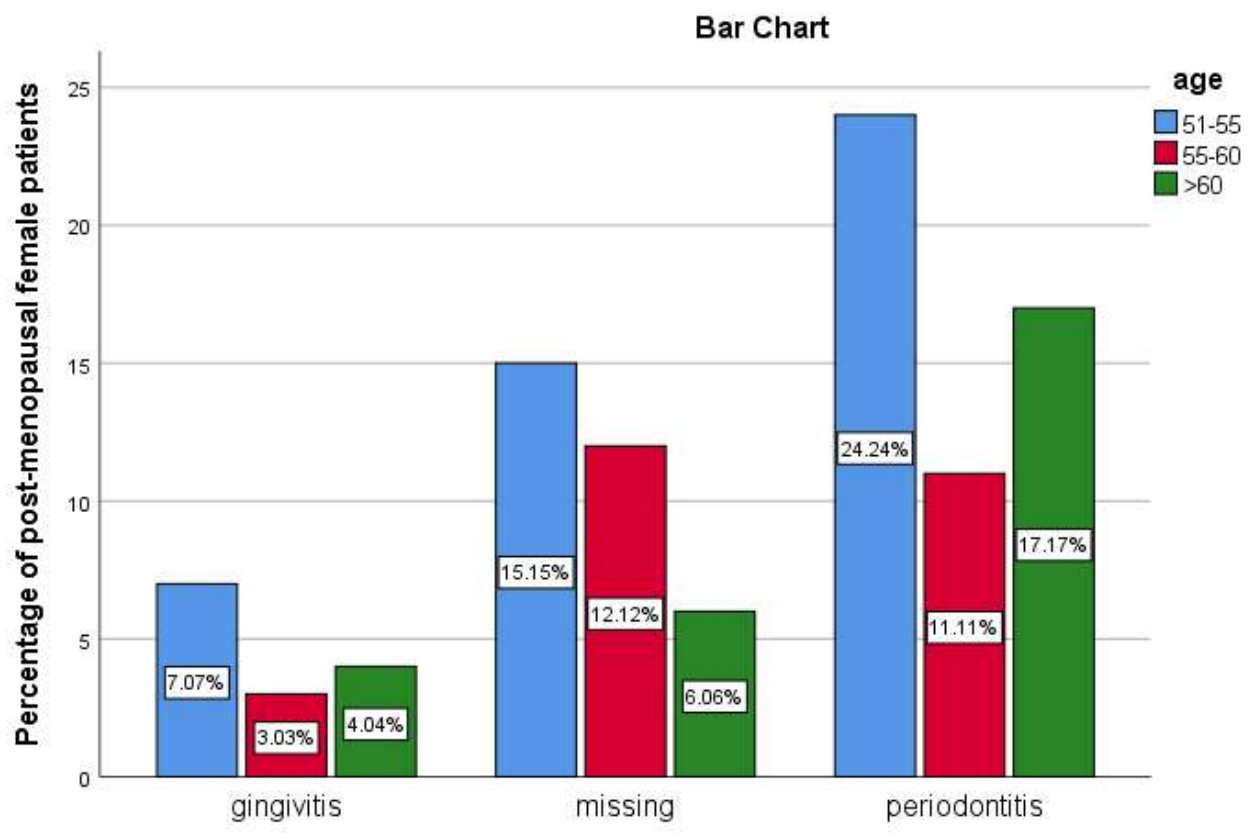

Periodontal status and tooth loss in relation to LtMan1M

Fig. 6: Bar graphs represent the association of periodontal status and tooth loss in relation to left mandibular first molar with age. $\mathrm{X}$-axis represents the periodontal status and tooth loss in relation to left mandibular first molar. Yaxis represents the percentage of post-menopausal female patients. Periodontitis in relation to left mandibular first molarn was more commonly present in patients in the age group of 51-55 years than any other age group in postmenopausal stage and this difference is statistically significant. (Chi-square test, Pearson's Chi-square value: 0.472 , DF:2, $p$ value: $0.025(p<0.05)$ which is statistically significant)). (LtMan1M - left mandibular first molar) 


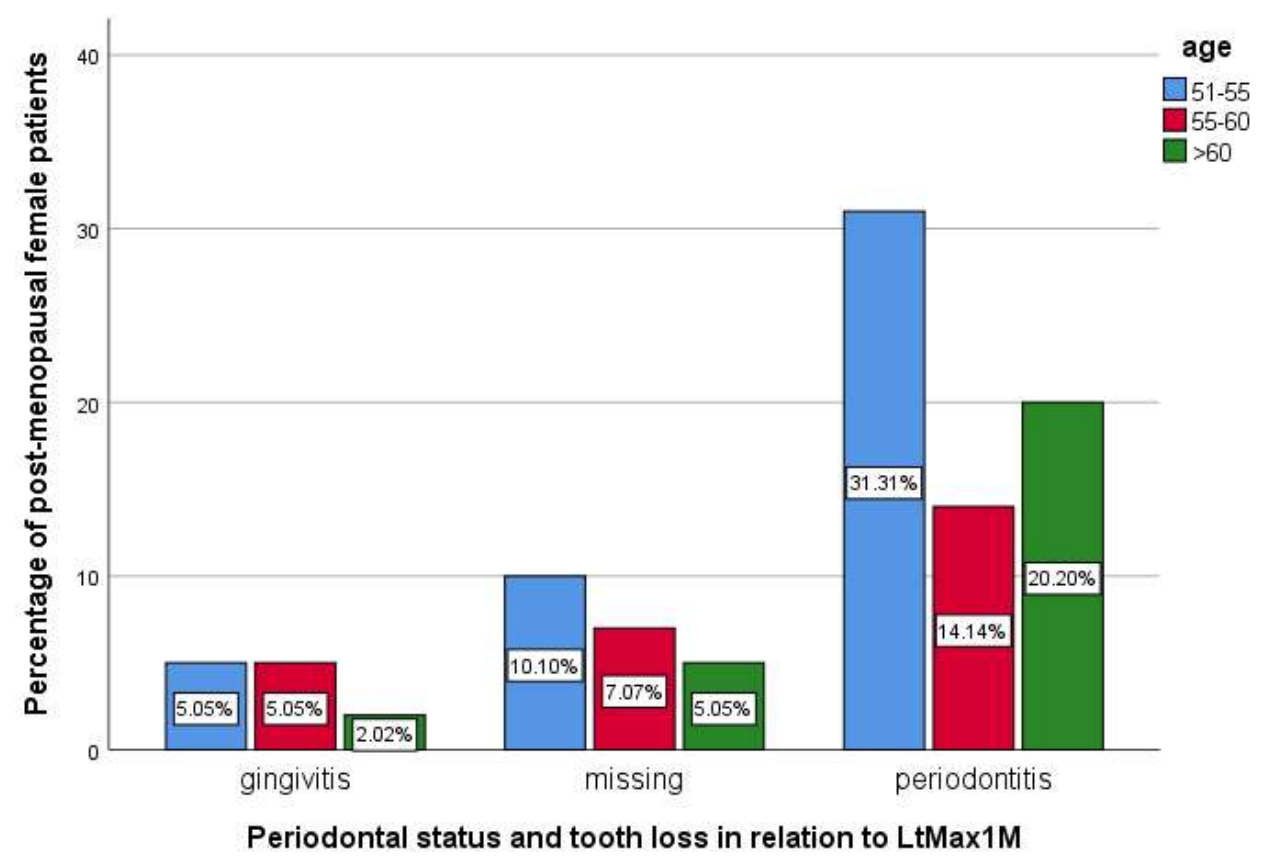

Fig. 7: Bar graphs represent the association of periodontal status and tooth loss in relation to left maxillary first molar with age. $\mathrm{X}$-axis represents the periodontal status and tooth loss in relation to the left maxillary first molar. Yaxis represents the percentage of post-menopausal female patients. Periodontitis in relation to left maxillary first molar was more commonly present in patients in the age group of 51-55 years than any other age group in postmenopausal stage and this difference is statistically significant. (Chi-square test, Pearson's Chi-square value: 0.412 , DF:2, p value: $0.025(p<0.05)$ which is statistically significant)). (LtMax1M - Left maxillary first molar)

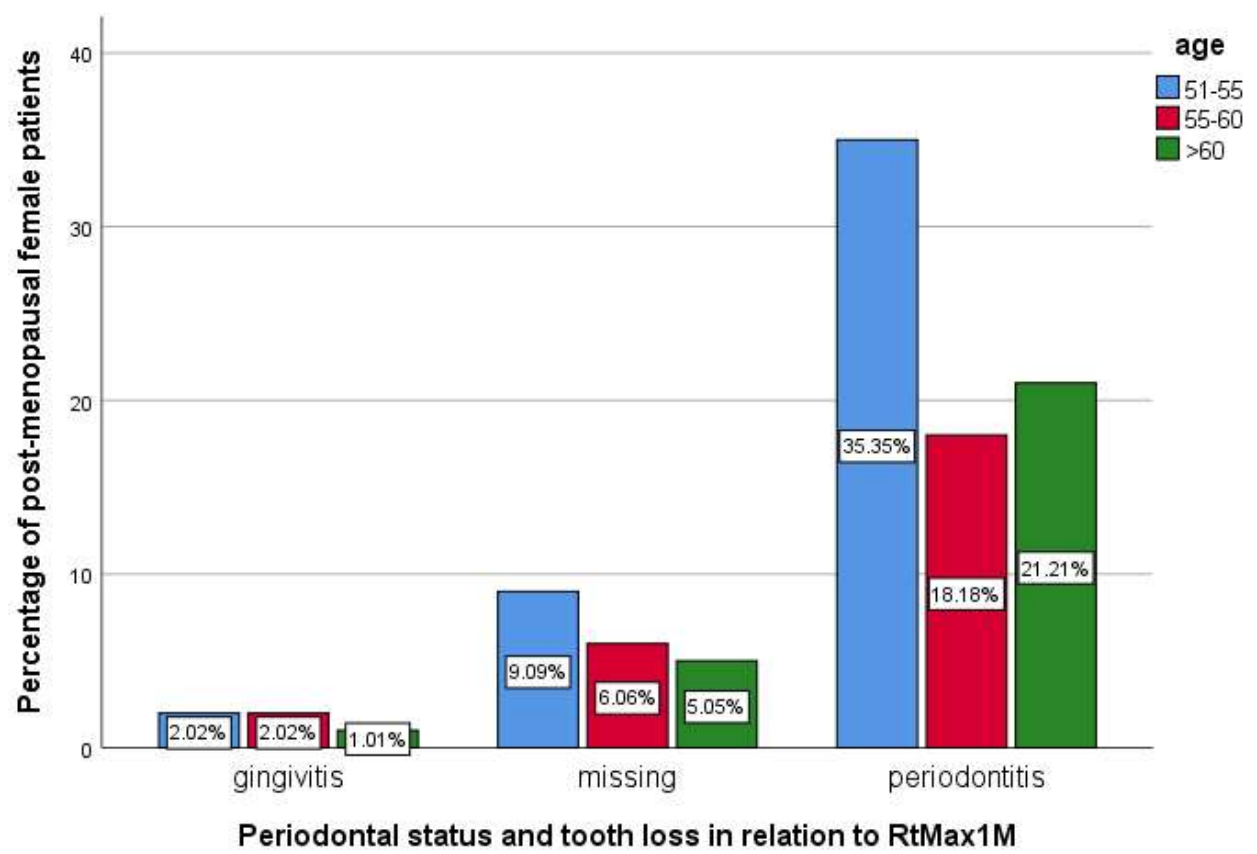

Fig. 8: Bar graphs represent the association of periodontal status and tooth loss in relation to right maxillary first molar with age. $X$-axis represents the periodontal status and tooth loss in relation to the right maxillary first molar. $\mathrm{Y}$-axis represents the percentage of post-menopausal female patients. Periodontitis in relation to right maxillary first molar was more commonly present in patients in the age group of 51-55 years than any other age group in postmenopausal stage and this difference is statistically significant. (Chi-square test, Pearson's Chi-square value: $0.434, \mathrm{DF}: 2$, $p$ value: $0.025(\mathrm{p}<0.05)$ which is statistically significant)). (RtMax1M - right maxillary first molar) 
Table 1: Frequency distribution of periodontal status and tooth loss in relation to maxillary and mandibular first molar teeth

\begin{tabular}{|c|c|c|c|c|}
\hline Tooth type & Gingivitis & Periodontitis & Missing teeth & Total \\
\hline $\begin{array}{c}\text { Right maxillary first } \\
\text { molar }\end{array}$ & 5 & 75 & 20 & 100 \\
\hline $\begin{array}{c}\text { Left maxillary first } \\
\text { molar }\end{array}$ & 12 & 65 & 23 & 100 \\
\hline $\begin{array}{c}\text { Right mandibular } \\
\text { first molar }\end{array}$ & 19 & 49 & 32 & 100 \\
\hline $\begin{array}{c}\text { Left mandibular } \\
\text { first molar }\end{array}$ & 15 & 52 & 33 & \\
\hline
\end{tabular}

\section{DISCUSSION}

Perimenopause is the turning point for physical, emotional and psychological changes in a woman's life. During this phase, various symptoms occur with different degrees, ranging from low, middle, high, occurring gradually between the age of 40 and 50 years. In the perimenopausal period hormonal imbalance occurs $[11,12]$. The highest prevalence of oral discomfort is seen during perimenopausal and post-menopausal periods.

The natural menopausal age is $45-55$ years. In a study, there was difference in age between perimenopausal women which was reported to be $47.33+/-2.49$ years and postmenopausal women which was reported to be $53.92+/-3.76$ years [13] Another study showed small average changes in probing measures and alveolar bone height during a 5-year interval. Mean changes showed loss of alveolar bone and periodontal disease progression, whereas clinical attachment loss (CAL) and pocket depth (PD) were stable $[\mathbf{1 2}, \mathbf{1 3}]$.
Tooth loss resulting from periodontal disease was low, occurring in $13 \%$ of females. Although oral hygiene was good at the baseline and follow up, there was a slight improvement in brushing and flossing habits. In the previous literature, tooth loss due to periodontitis has occurred in $14.7 \%$ of post-menopausal women and the attachment loss and the gingival recession were also higher in these women.

Older females and even smokers demonstrated greater CAL and increased PD compared with their younger and never smoker counterparts. Less periodontal disease progression was observed in postmenopausal females of history of hormone therapy use $[\mathbf{1 4}, \mathbf{1 5}]$. This study could be further improved by increasing the sample size and analysing various factors affecting periodontium during menopause and postmenopause periods.

\section{CONCLUSION}

Post-menopause condition has a drastic change in the health of an individual, especially oral health. Within the limitations of the study, the results showed that gingivitis and tooth more commonly 
seen in relation to mandibular first molar teeth than maxillary first molar teeth. Further, it is revealed that periodontitis in relation to maxillary first molar teeth was seen more commonly in patients in the age group 51-55 years of postmenopausal stage. This study emphasizes the need for preventive therapeutic measures in female patients at their perimenopausal and early postmenopausal stages.

\section{AUTHORS CONTRIBUTION}

First author performed the data collection by reviewing patient details, filtering required data,analysing and interpreting statistics and contributed to manuscript writing.

Second author contributed to conception of study title, study design, analysed the collected data,statistics and interpretation and also critically revised the manuscript.

Third author participated in the study and revised the manuscript. All the three authors have discussed the results and contributed to the final manuscript.

ACKNOWLEDGMENT This research was supported by Saveetha Dental College and Hospitals. We thank the department of Periodontics, Saveetha Dental College for providing insight and expertise that greatly assisted this research.

CONFLICT OF INTEREST: None declared
[1] Thamaraiselvan M, Elavarasu S, Thangakumaran S, Gadagi JS, Arthie T. Comparative clinical evaluation of coronally advanced flap with or without platelet rich fibrin membrane in the treatment of isolated gingival recession. Journal of Indian Society of Periodontology. 2015 Jan;19(1):66.

[2] Ramesh A, Varghese SS, Doraiswamy JN, Malaiappan S. Herbs as an antioxidant arsenal for periodontal diseases. Journal of intercultural ethnopharmacology. 2016 Jan;5(1):92 .

[3] Varghese SS, Thomas H, Jayakumar ND, Sankari M, Lakshmanan R. Estimation of salivary tumor necrosis factor-alpha in chronic and aggressive periodontitis patients. Contemporary clinical dentistry. 2015 Sep;6(Suppl 1):S152.

[4] Avinash K, Malaippan S, Dooraiswamy JN. Methods of isolation and characterization of stem cells from different regions of oral cavity using markers: a systematic review. International journal of stem cells. 2017 May;10(1):12.

[5] Panda S, Jayakumar ND, Sankari M, Varghese SS, Kumar DS. Platelet rich fibrin and xenograft in treatment of intrabony defect. Contemporary clinical dentistry. 2014 Oct;5(4):550.

[6] Mootha, A., Malaiappan, S., Jayakumar, N.D., Varghese, S.S., Toby Thomas, J. The Effect of Periodontitis on Expression of

\section{REFERENCES}


Interleukin-21: A Systematic Review. 2016. Article ID 3507503, 1-8

[7] Ravi, S., Malaiappan, S., Varghese, S., Jayakumar, N.D., Prakasam, G.Additive effect of plasma rich in growth factors with guided tissue regeneration in treatment of intrabony defects in patients with chronic periodontitis: A split-mouth randomized controlled clinical trial. Journal of Periodontology. 2017;88(9) :839- 845

[8] Khalid, W., Varghese, S.S., Sankari, M., Jayakumar, N.D.Comparison of serum levels of endothelin-1 in chronic periodontitis patients before and after treatment. Journal of Clinical and Diagnostic Research. 2017,11(4) ;78-81.

[9] Khalid, W., Vargheese, S.S., Lakshmanan, R., Sankari, M., Jayakumar, N.D.Role of endothelin-1 in periodontal diseases: A structured review. Indian Journal of Dental Research. 2016; 27(3), 323.

[10] Ramesh, A., Varghese, S.S., Jayakumar, N.D., Malaiappan, S.Chronic obstructive pulmonary disease and periodontitis - Unwinding their linking mechanisms. Journal of Oral Biosciences. 2016, 58(1), 23-26.

[11] Kavarthapu A, Thamaraiselvan M. Assessing the variation in course and position of inferior alveolar nerve among south Indian population: A cone beam computed tomographic study. Indian

Journal of Dental Research. 2018 Jul 1;29(4):405.

[12] Ramesh A, Ravi S, Kaarthikeyan G. Comprehensive rehabilitation using dental implants in generalized aggressive periodontitis. Journal of Indian Society of Periodontology. 2017 Mar;21(2):160.

[13] Ramesh A, Vellayappan R, Ravi S, Gurumoorthy K. Esthetic lip repositioning: A cosmetic approach for correction of gummy smile-A case series. Journal of Indian Society of Periodontology. 2019 May;23(3):290

[14] Priyanka S, Kaarthikeyan G, Nadathur JD, Mohanraj A, Kavarthapu A. Detection of cytomegalovirus, Epstein-Barr virus, and Torque Teno virus in subgingival and atheromatous plaques of cardiac patients with chronic periodontitis. Journal of Indian Society of Periodontology. 2017 Nov;21(6):456.

[15] Gajendran, P., Parthasarathy, H., Tadepalli, A.Comparative evaluation of cathepsin $\mathrm{K}$ levels in gingival crevicular fluid among smoking and nonsmoking patients with chronic periodontitis.Indian Journal of Dental Research. 2018;29(5) :588-593. 